\title{
Consumo de nutrientes, produção e composição do leite de ovelhas alimentadas com dietas contendo diferentes níveis de fibra em detergente neutro ${ }^{1}$
}

\section{Cristiano Haetinger Hübner ${ }^{2}$, Cleber Cassol Pires ${ }^{3}$, Diego Barcelos Galvani ${ }^{4}$, Sérgio Carvalho ${ }^{5}$, Tatiana Pfüller Wommer 6}

\author{
${ }^{1}$ Parte da Dissertação de Mestrado apresentada pelo primeiro autor à Universidade Federal de Santa Maria (UFSM) \\ 2 Mestre em Zootecnia, UFSM. \\ ${ }^{3}$ Departamento de Zootecnia, UFSM, Campus Camobi, CEP: 97105-900, Santa Maria, RS, Brasil. Pesquisador do CNPq. \\ ${ }^{4}$ Programa de Pós-graduação em Zootecnia, UFSM. \\ ${ }^{5}$ Centro Universitário, Feevale. \\ ${ }^{6}$ Curso de Zootecnia, UFSM.
}

RESUMO - O experimento foi desenvolvido com o objetivo de avaliar o efeito de diferentes níveis de fibra na dieta sobre o consumo de nutrientes e a produção e composição do leite de ovelhas. Dezoito ovelhas multíparas, confinadas 24 horas após o parto em baias individuais, foram distribuídas aleatoriamente em três níveis dietéticos de FDN (tratamento): 34, 43 e 52\%. As dietas, constituídas por mistura completa de silagem de milho e concentrado (grão de milho triturado, farelo de soja e mistura mineral) foram formuladas para serem isoprotéicas (13\% PB). A produção e a composição do leite foram avaliadas a cada sete dias, durante 42 dias. Houve influência do nível de FDN da dieta sobre os consumos de MS, MO, PB, EE, FDN, FDA, CNE e CT (kg/dia, \%PV e g/ $/ \mathrm{kPV}^{0,75}$ ), que apresentaram comportamento quadrático. O máximo consumo de MS estimado correspondeu ao nível de 42,7\% de FDN na dieta. Verificou-se efeito quadrático da produção de leite em função dos tratamentos, sendo a produção máxima estimada no nível de 39,8\% de FDN na dieta. A relação entre proteína do leite e nível de FDN da dieta foi quadrática. A quantidade de gordura (g/dia) e a densidade do leite decresceram linearmente com o incremento do nível FDN na dieta. A produção de sólidos totais (g/dia) e as produções de leite corrigidas para 3,5\% e para sólidos totais variaram de forma quadrática. O estádio da lactação influenciou a produção de leite, de modo que o pico da lactação situou-se entre a primeira e terceira semanas de lactação.

Palavras-chave: concentrado, FDN, leite, nutrição, ovinos

\section{Nutrient intake, milk yield and composition of ewes fed diet containing different neutral detergent fiber levels}

\begin{abstract}
The experiment was carried to evaluate the effect of different levels of fiber in the diet on the nutrients intake, daily milk yield and composition of ewes. Eighteen multiparous ewes, housed in individual cage 24 hours postpartum, were randomly assigned to three levels of dietary NDF (treatment): 34, 43 and 52\%. The diets constituted by a total mixed ration of corn silage, and a concentrate mix (ground corn, soybean meal and mineral mix) were formulated to be isoproteic (13\% CP). The milk yield and composition was evaluated at each week, during 42 days. The NDF levels quadratically affected the intakes of DM, OM, CP, EE, NDF, ADF, NSC and TC $\left(\mathrm{kg} / \mathrm{day}, \% \mathrm{BW}\right.$ and $\left.\mathrm{g} / \mathrm{kgBW}^{0.75}\right)$. The maximum intake of DM corresponded to the $42.7 \%$ of NDF level in the diet. Quadratic effect on the milk yield was verified, which was higher with $39.8 \%$ of NDF level. Quadratic effect on CP milk contents was observed. Milk fat contents (g/day) and milk density showed linear decrease with the increment of NDF level in the diet. Total solids contents (g/day), 3.5\% fat corrected milk yield and corrected for total solids showed a quadratic behavior. The stage of the lactation influenced the milk production, in way that the peak of the lactation can occurs between the first and the third week of lactation.
\end{abstract}

Key Words: concentrate, milk, NDF, nutrition, sheep

\section{Introdução}

Em razão de a crescente demanda por carne ovina, principalmente aquela proveniente de animais jovens, ter despertado nos produtores o interesse pela produção de cordeiros, tornou-se necessária a otimização do crescimento pré e pós-desmama. Durante as primeiras semanas de vida, o desempenho dos cordeiros depende, em grande parte, da produção de leite das ovelhas (Siqueira, 1996). 
A condição nutricional no período pós-parto afeta diretamente a quantidade de leite produzida por ovelhas em lactação, de modo que o pico de produção situa-se entre a terceira e quarta semanas pós-parto (Siqueira, 1996). Neste período, geralmente observa-se perda de peso das ovelhas, a qual depende da qualidade e quantidade de alimento disponível, assim como do número de cordeiros amamentados, de fatores ambientais e do potencial produtivo da ovelha (Susin, 1996). Da mesma forma, a nutrição no período pré-parto também afeta a produção de leite (Treacher, 1989)

Estudos (Van Soest, 1994; Jung \& Allen, 1995; Bürger et al., 2000; Cardoso et al., 2006) têm demonstrado correlação negativa elevada entre o consumo de MS e o teor de FDN da dieta, associando este fato à menor digestibilidade da fração fibrosa em relação aos demais constituintes dietéticos, o que pode resultar em maior tempo de permanência da digesta no retículo-rúmen e, por conseqüência, na repleção ruminal. Segundo Turino (2003), dependendo de sua concentração e digestibilidade, a FDN pode impor limitações sobre o consumo de MS e energia, restringindo o desempenho produtivo dos animais. Entretanto, a saúde dos ruminantes depende diretamente de concentrações mínimas de FDN na ração, de forma a manter atividade de mastigação e motilidade ruminal adequadas (Mertens, 1997).

Carvalho et al. (2006) avaliaram o consumo de nutrientes e o desempenho de cabras leiteiras e observaram decréscimo da produção de leite, na medida em que o nível de FDN aumentava. Da mesma forma, alterações na concentração dietética de fibra podem afetar a composição do leite produzido, principalmente quanto ao teor de gordura do mesmo (Lammers et al., 1996). Sakul \& Boylan (1992), avaliando a composição do leite de ovelhas de diversas raças, puras e sintéticas, obtiveram valores médios de 6,0; 5,8; 4,8 e 17,4\%, respectivamente, para gordura, $\mathrm{PB}$, lactose e sólidos totais.

A utilização de dietas com níveis adequados de FDN para ovelhas na fase de lactação poderá causar impacto nos sistemas de produção de carne ovina, em virtude da melhor nutrição dos cordeiros. Assim, objetivou-se com este trabalho avaliar o consumo de nutrientes, a produção e a composição do leite de ovelhas alimentadas com níveis crescentes de FDN.

\section{Material e Métodos}

O experimento foi realizado no Laboratório de Ovinocultura do Departamento de Zootecnia da Universidade Federal de Santa Maria, localizada na região fisiográfica denominada Depressão Central do Estado do Rio Grande do Sul, situada a $29^{\circ} 42^{\prime} \mathrm{S}$ de latitude, $53^{\circ} 48^{\prime} \mathrm{W}$ de longitude e 95 m de altitude em relação ao nível do mar. O clima na região, segundo a classificação de Köppen, é o do tipo Cfa, subtropical úmido (Moreno, 1961).

Foram utilizadas 18 ovelhas provenientes do cruzamento alternado entre as raças Texel e Ile de France, multíparas, paridas de cordeiros machos, confinadas 24 horas após o parto em baias individuais (aproximadamente $2 \mathrm{~m}^{2}$ ), equipadas com comedouros e bebedouros. Os comedouros das ovelhas foram dispostos a $60 \mathrm{~cm}$ de altura do piso, de forma a evitar o consumo de alimento por parte dos cordeiros, os quais tinham acesso a comedouros privativos.

Os animais (ovelha + cordeiro) foram distribuídos aleatoriamente em três tratamentos: 34, 43 e 52\% de FDN na dieta, na base da MS. Durante o terço final de gestação, as ovelhas foram alimentadas com a dieta intermediária (43\% FDN). As dietas, compostas por silagem de milho (Zea mays L.), milho triturado, farelo de soja (Glycine max L.), calcário calcítico, fosfato bicálcico e sal comum, foram calculadas com base nas exigências preconizadas pelo NRC (1985) para serem isoprotéicas (Tabela 1). O arraçoamento foi feito ad libitum, duas vezes ao dia ( $8 \mathrm{~h} 30$ e $16 \mathrm{~h} 30)$, sendo a quantidade ofertada ajustada de forma a manter as sobras em, aproximadamente, $10 \%$ do total oferecido.

Diariamente, foram coletadas amostras dos alimentos fornecidos e das respectivas sobras, as quais foram identificadas e acondicionadas em freezer à temperatura de $-10^{\circ} \mathrm{C}$ para posteriores análises laboratoriais. As amostras foram pré-secas em estufa ventilada a $65^{\circ} \mathrm{C}$ e, posteriormente, trituradas em moinho tipo "Willey" com peneira de poro de $1 \mathrm{~mm}$. A determinação dos teores de MS, MO, FDN, FDA, PB e EE foi realizada segundo metodologia descrita por Silva \& Queiroz (2002). Os teores de CT foram calculados segundo Sniffen et al. (1992), em que CT (\%) = $100-(\% \mathrm{~PB}+\% \mathrm{EE}+\% \mathrm{CIN})$, e os teores de CNE, pela diferença de CT - FDN. Os valores de EM foram estimados com base nas equações propostas por Weiss et al. (1992) e pelo NRC (1989).

O consumo de nutrientes correspondeu à diferença entre o alimento ofertado e suas sobras. Os animais foram pesados a cada 21 dias, precedidos de jejum de sólidos por aproximadamente 14 horas, quando também foi realizada a avaliação do escore de condição corporal, segundo a metodologia descrita por Russel (1969), com escala variando de 1 (muito magra) a 5 (muito gorda).

A produção de leite foi determinada pelo método indireto da dupla pesagem, proposto por Doney et al. (1979), de modo que os cordeiros foram mantidos separados das ovelhas, pesados individualmente em balança digital e imediatamente levados para amamentação até a saciedade, 
Tabela 1 - Composições percentual e bromatológica das dietas experimentais

Table 1 - Percentage and chemical compositions of the experimental diets

\begin{tabular}{|c|c|}
\hline \multirow[t]{2}{*}{ Item (\%) } & $\begin{array}{l}\text { Nível de FDN na dieta (\%) } \\
\text { NDF level in the diet (\%) }\end{array}$ \\
\hline & 43 \\
\hline
\end{tabular}

Composição percentual (\% MS)

Percentage composition (\% DM)

\begin{tabular}{lrrr}
\hline Silagem de milho (Corn silage) & 47,59 & 65,18 & 82,60 \\
Milho triturado (Ground corn) & 38,04 & 18,95 & 0,00 \\
Farelo de soja (Soybean meal) & 12,95 & 14,64 & 16,32 \\
Calcário calcítico (Limestone) & 0,80 & 0,54 & 0,30 \\
Fosfato bicálcico (Dicalcium phosphate) & 0,02 & 0,10 & 0,18 \\
Sal (Salt) & 0,60 & 0,60 & 0,60
\end{tabular}

Composição bromatológica (\% MS)

Chemical composition (\% DM)

\begin{tabular}{lrrr}
\hline MS (DM) & 60,32 & 49,07 & 37,88 \\
MO (OM) & 95,27 & 94,79 & 94,27 \\
PB (CP) & 13,15 & 13,26 & 13,37 \\
FDN (NDF) & 34,48 & 43,50 & 52,44 \\
FDA (ADF) & 18,21 & 23,36 & 28,46 \\
CT (TC) & 76,50 & 76,82 & 77,11 \\
CNE (NSE) & 44,34 & 34,95 & 25,62 \\
EE & 3,31 & 3,07 & 2,84 \\
EM (ME), Mcal/kg & 2,74 & 2,60 & 2,45 \\
Ca & 0,33 & 0,31 & 0,31 \\
P & 0,19 & 0,17 & 0,17 \\
\hline
\end{tabular}

quando foram pesados novamente. A diferença entre o peso do cordeiro antes e depois de mamar correspondeu à quantidade de leite produzido pela ovelha. Este procedimento foi realizado por 6 semanas consecutivas, uma vez a cada semana, com intervalos de 6 horas entre as pesagens, até que se completassem as 24 horas do dia.

Da mesma forma, uma vez a cada semana, no período matutino, foram coletadas amostras de leite para determinação dos teores de gordura, lactose e proteína, além da densidade. Para determinação do teor de gordura do leite, foi utilizado o aparelho Gerber Milk Test, previamente calibrado com leite de ovelha. A concentração de proteína foi determinada pelo método micrométrico de kjeldahl (AOAC, 1995) e o teor de lactose, pelo título do Licor de Feeling (Brasil, 1981). A densidade (D) foi determinada por termolactodensímetro, corrigindo-se o efeito da temperatura (Brasil, 1981). Para estimativa da concentração de sólidos totais (ST), foi adotada a fórmula de Fleishmann (Silva, 1997), em que ST = 1,2*\% Gordura + 2,665 [(100*D - 100)/D]. A produção de leite foi, ainda, corrigida para $3,5 \%$ de gordura (Gaines, 1928), em que LCG3, $5=(0,4255 *$ kg leite $)+[16,425 *(\%$ gordura $/ 100) * k g$ leite], e para sólidos totais (Tyrrell \& Reid, 1965): $\mathrm{LCST}=(12,3 * \mathrm{~g}$ de gordura $)+(6,56 * \mathrm{~g}$ de sólidos nãogordurosos $)-(0,0752 * \mathrm{~kg}$ de leite $)$.
O delineamento experimental utilizado foi o inteiramente casualizado com três tratamentos e seis repetições. Os dados foram submetidos à análise de variância, cujo modelo estatístico utilizado foi:

$$
\mathrm{Y}_{\mathrm{ij}}=\mu+\tau_{\mathrm{i}}+\varepsilon_{\mathrm{ij}}
$$

em que $Y_{i j}$ refere-se a observações das variáveis correspondentes à repetição j sob o tratamento de ordem $\mathrm{i} ; \mu$, à média geral das observações; $\tau_{\mathrm{i}}$, ao efeito do tratamento de ordem $\mathrm{i} ; \varepsilon_{\mathrm{ij}}$, ao erro aleatório associado à repetição de ordem j sob o tratamento de ordem i.

Após selecionado o erro pelo modelo, os dados foram ajustados ao seguinte modelo de regressão polinomial:

$$
\mathrm{Y}_{\mathrm{ij}}=\alpha+\beta_{1} \mathrm{x}_{\mathrm{ij}}+\beta_{2} \mathrm{x}^{2}{ }_{\mathrm{ij}}+\varphi+\varepsilon_{\mathrm{ij}}
$$

em que $Y_{i j}$ refere-se às observações das variáveis dependentes correspondentes à repetição da variável independente j sob o tratamento de ordem i; $\alpha, \beta_{1}$ e $\beta_{2}$, aos parâmetros da equação; $x_{i j}$, à observação da variável independente associado à repetição de ordem $\mathrm{j}$ sob tratamento de ordem $\mathrm{i} ; \varphi$, aos desvios da regressão; $\varepsilon_{\mathrm{ij}}$, ao erro aleatório residual determinado no modelo anterior.

O modelo adotado, segundo o grau da polinomial, foi selecionado de acordo com a significância do teste $\mathrm{F}$ e o coeficiente de determinação, adotando-se o nível de $5 \%$ de probabilidade. As análises foram realizadas com auxílio do pacote estatístico SAS (1997).

\section{Resultados e Discussão}

Houve influência do nível de FDN da dieta $(\mathrm{P}<0,05)$ sobre os consumos dos nutrientes ( $\mathrm{kg} / \mathrm{dia}, \% \mathrm{PV}$ e $\mathrm{g} / \mathrm{kg}$ $\mathrm{PV}^{0,75}$, Tabela 2), que apresentaram comportamento quadrático.

Em cabras lactantes alimentadas com níveis crescentes de FDN, Carvalho et al. (2006) verificaram aumento linear dos consumos de FDN e FDA, ao passo que os de MS, MO, $\mathrm{PB}, \mathrm{EE}, \mathrm{CT}$ e CNE diminuíram linearmente com o aumento do nível de fibra na dieta, diferentemente dos resultados observados neste estudo, atribuindo aqueles resultados à variação dos teores destas frações nas dietas experimentais, com o acréscimo de volumoso na dieta. Cardoso et al. (2006), trabalhando com cordeiros em terminação, também relataram efeito linear do nível de FDN da dieta sobre o consumo de nutrientes. Segundo Van Soest (1994), uma vez o teor de parede celular é limitante da ingestão, a capacidade ingestiva máxima será constante.

O máximo consumo estimado de MS (kg/dia) correspondeu ao nível de 42,8\% de FDN na dieta. A elevação do consumo de nutrientes até este nível pode ser explicada, entre outros fatores, pela demanda fisiológica do animal. Mertens (1997) salienta que animais alimentados com dietas 
que contêm menores níveis de FDN apresentam consumo para manter uma ingestão constante de energia, e a ingestão de MS poderá decrescer com o aumento da digestibilidade

Tabela 2 - Valores médios para os consumos diários de nutrientes (kg/dia, \%PV e g/kg PV $\left.{ }^{0,75}\right)$, de acordo com o nível de FDN da dieta

Table 2 - Means values for the daily nutrient intakes ( $\mathrm{kg} / \mathrm{day}, \% \mathrm{BW}$ and $\mathrm{g} / \mathrm{kg} B \mathrm{~W}^{0.75}$ ) according to the dietary NDF levels in the diet

\begin{tabular}{|c|c|c|c|c|c|c|}
\hline \multirow[t]{2}{*}{$\begin{array}{l}\text { Consumo } \\
\text { Intake }\end{array}$} & \multicolumn{3}{|c|}{$\begin{array}{c}\text { Nível de FDN } \\
\text { na dieta (\%) } \\
\text { NDF level in the diet }\end{array}$} & \multirow[t]{2}{*}{$\mathrm{R}^{2}$} & \multirow[t]{2}{*}{ CV (\%) } & \multirow[t]{2}{*}{$\begin{array}{l}\text { Regressãc } \\
\text { Regressior }\end{array}$} \\
\hline & 34 & 43 & 52 & & & \\
\hline & \multicolumn{3}{|c|}{$\mathrm{kg} / \mathrm{d}$} & & & \\
\hline MS (DM) & 1,766 & 2,091 & 1,757 & 0,27 & 14,88 & 1 \\
\hline $\mathrm{MO}(\mathrm{OM})$ & 1,685 & 1,983 & 1,658 & 0,27 & 14,89 & 2 \\
\hline $\mathrm{PB}(C P)$ & 0,245 & 0,295 & 0,248 & 0,30 & 14,38 & 3 \\
\hline $\mathrm{EE}$ & 0,062 & 0,068 & 0,053 & 0,40 & 14,13 & 4 \\
\hline FDN (NDF) & 0,578 & 0,879 & 0,911 & 0,63 & 15,66 & 5 \\
\hline FDA (ADF) & 0,305 & 0,471 & 0,492 & 0,64 & 15,94 & 6 \\
\hline CT (TC) & 1,334 & 1,581 & 1,339 & 0,25 & 15,07 & 7 \\
\hline CNE (NSC) & 0,800 & 0,743 & 0,446 & 0,74 & 14,85 & 8 \\
\hline \multicolumn{6}{|c|}{.............. \%PV (\%BW) } & \\
\hline MS (DM) & 3,36 & 3,67 & 2,93 & 0,49 & 10,03 & 9 \\
\hline $\mathrm{MO}(\mathrm{OM})$ & 3,21 & 3,48 & 2,77 & 0,51 & 10,02 & 10 \\
\hline $\mathrm{PB}(C P)$ & 0,47 & 0,52 & 0,41 & 0,52 & 9,45 & 11 \\
\hline $\mathrm{EE}$ & 0,12 & 0,12 & 0,09 & 0,74 & 8,36 & 12 \\
\hline FDN (NDF) & 1,10 & 1,54 & 1,52 & 0,67 & 11,03 & 13 \\
\hline FDA (ADF) & 0,58 & 0,83 & 0,82 & 0,68 & 11,35 & 14 \\
\hline $\mathrm{CT}(T C)$ & 2,54 & 2,77 & 2,23 & 0,47 & 10,24 & 15 \\
\hline CNE (NSC) & 1,52 & 1,31 & 0,74 & 0,91 & 9,33 & 16 \\
\hline \multicolumn{6}{|c|}{$\ldots \ldots \ldots \ldots \ldots . \mathrm{g} / \mathrm{kg} \mathrm{PV}^{0,75}\left(\mathrm{~g} / \mathrm{kg} B W^{0.75}\right)$} & \\
\hline MS (DM) & 90,43 & 100,75 & 81,59 & 0,44 & 10,63 & 17 \\
\hline $\mathrm{MO}(\mathrm{OM})$ & 86,29 & 95,54 & 76,94 & 0,45 & 10,62 & 18 \\
\hline $\mathrm{PB}(C P)$ & 12,53 & 14,22 & 11,51 & 0,47 & 10,15 & 19 \\
\hline $\mathrm{EE}$ & 3,17 & 3,30 & 2,45 & 0,66 & 9,66 & 20 \\
\hline FDN (NDF) & 29,62 & 42,36 & 42,23 & 0,68 & 11,64 & 21 \\
\hline FDA $(A D F)$ & 15,62 & 22,69 & 22,83 & 0,69 & 11,85 & 22 \\
\hline CT (TC) & 68,30 & 76,21 & 62,14 & 0,41 & 10,79 & 23 \\
\hline CNE (NSC) & 40,96 & 35,84 & 20,72 & 0,89 & 10,07 & 24 \\
\hline
\end{tabular}

1. $\hat{\mathrm{Y}}=-4,422+0,308$ FDN $-0,0036$ FDN $^{2 *} ; 2 . \hat{\mathrm{Y}}=-4,129+0,291$ FDN $-0,0034 \mathrm{FDN}^{2} * 3 . \hat{\mathrm{Y}}=-0,677+0,046 \mathrm{FDN}-0,0005 \mathrm{FDN}^{2} * 4 . \hat{\mathrm{Y}}=-0,134$ $+0,010$ FDN $-0,00012$ FDN $^{2} ; 5 . \hat{\mathrm{Y}}=-2,613+0,148 \mathrm{FDN}-0,0015 \mathrm{FDNN}^{2 *}$; 6. $\hat{\mathrm{Y}}=-1,422+0,079 \mathrm{FDN}-0,00082 \mathrm{FDN}^{2} * 7 . \hat{\mathrm{Y}}=-3,298+0,230 \mathrm{FDN}$ $-0,0027 F_{D N}{ }^{2 *} ; 8 . \hat{\mathrm{Y}}=-0,778+0,090 \mathrm{FDN}-0,0013 \mathrm{FDN}^{2} * 9 . \hat{\mathrm{Y}}=-5,653$ $+0,463^{* *}$ FDN $-0,0057^{* *} F_{D N}{ }^{2} ; 10 . \hat{Y}=-5,206+0,434^{* * F D N}$ $-0,0054^{* \star} \mathrm{FDN}^{2} ; 11 . \hat{\mathrm{Y}}=-0,895+0,069^{* *} \mathrm{FDN}-0,0008^{* *} \mathrm{FDN}^{2}$; 12. $\hat{\mathrm{Y}}=-0,136+0,014^{* *} \mathrm{FDN}-0,00018^{* *} \mathrm{FDN} \mathrm{N}^{2} ; 13 . \hat{\mathrm{Y}}=-4,109+$ $0,245^{*} \mathrm{FDN}-0,0026^{* *} \mathrm{FDN}{ }^{2} ; 14 . \hat{\mathrm{Y}}=-2,240+0,133^{*} \mathrm{FDN}-0,0014^{*} \mathrm{FDN}^{2}$; 15. $\hat{Y}=-4,213+0,346^{* *} F D N-0,0043^{* *} F^{2} N^{2} ; 16 . \hat{Y}=-0,243+$ $0,114^{*}$ FDN $-0,0018^{* *} F^{2} N^{2} ; 17 . \hat{Y}=-107,543+13,301^{* * F D N}-$ $0,1629^{\star *} \mathrm{FDN} 2 ; 18 . \hat{\mathrm{Y}}=-158,360+12,504^{* \star} \mathrm{FDN}-0,1537^{\star *} \mathrm{FDN}{ }^{2} ;$ 19. $\hat{\mathrm{Y}}=-26,891+1,998^{* *} \mathrm{FDN}-0,0243^{* *} \mathrm{FDN}^{2} ; 20 . \hat{\mathrm{Y}}=-4,752+$ $0,418^{* \star} \mathrm{FDN}-0,0054^{* \star} \mathrm{FDN} 2 ; 21 . \hat{\mathrm{Y}}=-116,420+6,856^{* *} \mathrm{FDN}-$ $0,0732^{* *} \mathrm{FDN}^{2} ; 22 . \hat{\mathrm{Y}}=-63,838+3,718^{*} \mathrm{FDN}-0,0395^{*} \mathrm{FDN}^{2} ;$ 23. $\hat{\mathrm{Y}}=-127,244+9,950^{* *} \mathrm{FDN}-0,1215^{* *} \mathrm{FDN}{ }^{2} ; 24 . \hat{\mathrm{Y}}=-13,809+$ $3,405^{\star} F D N-0,0529^{* *}$ FDN $^{2}$.

*, ${ }^{* *} P<0,05$ e $P<0,01$, respectivamente, pelo teste $F(P<0.05$ and $P<0.01$ by Ftest). e do teor energético do alimento. Bull et al. (1976) descreveram que a relação entre a ingestão de MS e o conteúdo de FDN da dieta pode ser interpretada de forma quadrática, havendo um ponto de transição entre o controle físico e o fisiológico, no qual o efeito da repleção ruminal pela presença da fibra deixa de ocorrer, e o consumo passa a ser regulado pela ingestão de energia.

Não houve efeito significativo $(\mathrm{P}>0,05)$ das dietas sobre o peso final e o ganho médio diário (GMD) (Tabela 3). A condição corporal reflete o estado nutricional das ovelhas (Russel et al., 1969), sendo observada, neste estudo, relação quadrática entre a condição corporal final (CCF) e o nível de FDN da dieta $(\mathrm{P}<0,05)$. O nível de FDN relacionado à maior condição corporal, estimado pela equação de regressão (Tabela 3), foi de $44 \%$, próximo ao estimado para o consumo máximo de MS (42,8\%). Susin et al. (1995) ressaltaram que o sucesso de sistemas de produção intensiva de cordeiros depende, entre outros fatores, da manutenção ou incremento do estado corporal das ovelhas durante a lactação, uma vez que o período de anestro pós-parto é diretamente afetado. Os autores destacam, ainda, que a potencialização do desempenho reprodutivo de ovelhas de raças mais prolíficas, caso das raças especializadas para produção de carne, depende da adequada manutenção da boa condição física e das reservas do animal durante todo o ciclo anual. Desta forma, a manutenção da condição corporal adequada (em torno de 3,0) durante a lactação garante melhor eficiência reprodutiva posteriormente, com

Tabela 3 - Valores médios para desempenho e condição corporal das ovelhas, de acordo com o nível de FDN da dieta

Table 3 - $\quad$ Means values for performance and body condition of ewes according to the dietary NDF levels

\begin{tabular}{lcccccc}
\hline Item & \multicolumn{2}{c}{$\begin{array}{c}\text { Nível de FDN } \\
\text { na dieta (\%) }\end{array}$} & & $\mathrm{R}^{2}$ & $\mathrm{CV}$ (\%) & $\begin{array}{c}\text { Regressão } \\
\text { Regression }\end{array}$ \\
& \multicolumn{2}{c}{$\begin{array}{l}\text { NDF level in the diet } \\
\end{array}$} & & & & \\
\cline { 2 - 4 } & 34 & 43 & 52 & & & \\
\hline PI, kg & 53,32 & 56,03 & 57,76 & - & 7,91 & $\hat{\mathrm{Y}}=55,72$ \\
$\begin{array}{l}\text { IBW } \\
\text { PF, kg }\end{array}$ & 53,90 & 57,75 & 58,02 & - & 9,44 & $\hat{\mathrm{Y}}=56,63$ \\
$\begin{array}{l}\text { FBW } \\
\text { CCI }\end{array}$ & 2,40 & 3,16 & 3,10 & - & 19,31 & $\hat{\mathrm{Y}}=2,90$ \\
$\begin{array}{l}\text { IBCS } \\
\text { CCF }\end{array}$ & 2,60 & 3,58 & 3,20 & 0,54 & 13,06 & 1 \\
$\begin{array}{l}\text { FBCS } \\
\text { GMD } \\
\text { (kg/dia) }\end{array}$ & 0,013 & 0,040 & 0,006 & - & 37,01 & $\hat{\mathrm{Y}}=0,021$ \\
ADG & & & & & & \\
\hline
\end{tabular}

$\mathrm{PI}$ - peso inicial, PF - peso final, $\mathrm{CCl}$ - condição corporal inicial, CCF condição corporal final e GMD - ganho diário de peso.

IBW-initial body weight IW, final body weight (FBW), IBCS - initial body condition score, FBCS - final body condition score.

1. $\hat{\mathrm{Y}}=-11,478+0,6815 F D N-0,0077 F^{2} N^{2}$ **

** $P<0,01$ pelo teste $F(P<0.01$ by $F$ test $)$. 
reflexos positivos sobre a economicidade do sistema produtivo. Além disso, ovelhas passíveis de descarte apresentariam condição próxima à ideal para o abate.

Observou-se comportamento quadrático $(\mathrm{P}<0,05)$ da produção de leite em função do nível de FDN da dieta (Tabela 4), estimando-se a produção máxima quando as ovelhas foram alimentadas com uma dieta contendo 39,8\% de FDN. A quantidade (g/dia) e a concentração (\%) de proteína do leite variaram quadraticamente $(\mathrm{P}<0,05)$, com pontos de máxima estimados nos níveis de 27 e 59,5\% de FDN na dieta, respectivamente. Não houve efeito significativo $(\mathrm{P}>0,05)$ dos tratamentos sobre os teores $(\%)$ de gordura, lactose e sólidos totais do leite, observando-se médias de 3,90; 5,26 e 11,47\%, respectivamente. A quantidade de gordura produzida diariamente, assim como a densidade do leite, diminuiu linearmente $(\mathrm{P}<0,05)$ com o aumento do teor de FDN na dieta. A quantidade (g/dia) de sólidos totais e os valores de LCG3,5 e LCST variaram de modo quadrático $(\mathrm{P}<0,05)$, em função do nível de FDN.

Possivelmente o conteúdo energético da dieta, associado ao consumo de nutrientes (Tabela 2), que parece ter sido restringido pelo enchimento do retículo-rúmen, à medida que se elevou o nível de FDN da dieta, limitou a produtividade dos animais submetidos ao maior nível de FDN. Avaliando a produção e composição do leite ovino, Zeppenfeld (2003) verificou que a quantidade de leite produzido pelas ovelhas é influenciada pela dieta, sendo que uma relação volumoso:concentrado de 60:40 (37,15\% de FDN) resultou em maior produção de leite.

Segundo Wohlt et al. (1981), a composição do leite é diretamente afetada pela nutrição da ovelha, uma vez que influencia a fermentação ruminal e, assim, a disponibilidade de precursores para a síntese de gordura, proteína e lactose. Cabe salientar, neste sentido, o efeito preponderante da efetividade física da fibra dietética sobre o percentual de gordura do leite. De acordo com Lammers et al. (1996), a redução do nível de fibra da dieta promove diminuição do tempo gasto com mastigação (ingestão e ruminação) e, consequëntemente, do pH ruminal, uma vez que há menor fluxo de saliva para o rúmen, reduzindo o fluxo de substâncias tamponantes, o que pode desfavorecer o crescimento de microrganismos celulolíticos e a relação acetato:propionato e, desta forma, afetar o teor de gordura do leite. Neste estudo, como o teor de gordura não foi influenciado pelos níveis de fibra, pode-se inferir que as dietas contendo os menores níveis de FDN não ocasionaram falta de efetividade.

Bencini \& Pulina (1997) destacaram a existência de correlação negativa entre a produção de leite e as quantidades de gordura, além de variações na composição entre os diferentes estádios da lactação. Assim, a maior produção de leite observada nos animais alimentados com níveis intermediários de FDN pode ter acarretado diminuição na quantidade de gordura produzida diariamente. Por outro

Tabela 4 - Valores médios para produção diária de leite (Leite), proteína, gordura e lactose e sólidos totais (ST) e estimativas da densidade e produção de leite corrigida para 3,5 de gordura (LCG3,5) e para sólidos totais (LCST), de acordo com o nível de FDN da dieta

Table 4 - Means values of milk yield (Milk), protein, fat, lactose and total solids (TS), and estimates of milk density (Density) and corrected for 3.5\% fat (FAM3.5) and total solids milk yield (TSAM) according to the dietary NDF levels

\begin{tabular}{|c|c|c|c|c|c|c|}
\hline \multirow[t]{2}{*}{ Item } & \multicolumn{3}{|c|}{$\begin{array}{c}\text { Nível de FDN na dieta (\%) } \\
\text { NDF level in the diet }\end{array}$} & \multirow[t]{2}{*}{$\mathrm{R}^{2}$} & \multirow[t]{2}{*}{ CV (\%) } & \multirow[t]{2}{*}{$\begin{array}{l}\text { Regressão } \\
\text { Regression }\end{array}$} \\
\hline & 34 & 43 & 52 & & & \\
\hline Leite (Milk), g/d & $1.583,28$ & $1.670,56$ & $1.393,61$ & 0,07 & 27,47 & 1 \\
\hline Proteína (Protein), g/d & 76,41 & 81,03 & 63,48 & 0,11 & 28,45 & 2 \\
\hline Proteína (Protein), \% & 4,83 & 4,89 & 4,56 & 0,06 & 11,86 & 3 \\
\hline Gordura (Fat), g/d & 64,10 & 63,53 & 52,04 & 0,06 & 31,41 & 4 \\
\hline Gordura (Fat), \% & 4,10 & 3,84 & 3,79 & - & 22,22 & $\hat{\mathrm{Y}}=3,90$ \\
\hline Lactose, g/d & 83,75 & 87,62 & 72,72 & 0,07 & 27,34 & 5 \\
\hline Lactose, \% & 5,30 & 5,27 & 5,22 & - & 6,26 & $\hat{\mathrm{Y}}=5,26$ \\
\hline ST (TS), g/d & 184,27 & 189,50 & 156,94 & 0,08 & 27,17 & 6 \\
\hline ST (TS), \% & 11,70 & 11,39 & 11,33 & - & 9,09 & $\hat{\mathrm{Y}}=11,47$ \\
\hline Densidade (Density) & $1.038,80$ & $1.037,99$ & $1.037,32$ & 0,16 & 0,13 & 7 \\
\hline LCG3,5 (FAM3.5), g/d & $1.726,54$ & $1.754,27$ & $1.447,81$ & 0,08 & 27,95 & 8 \\
\hline LCST (TSAM), g/d & $1.462,80$ & $1.487,21$ & $1.227,63$ & 0,08 & 27,90 & 9 \\
\hline
\end{tabular}

1. $\hat{Y}=-1484,14+159,199 F D N-2,001 F D N 2 * ; 2 . \hat{Y}=-107,480+9,5965 F D N-0,1216 F D N 2 * * ; 3 . \hat{Y}=1,644+0,1676 F D N-0,0031 F D N 2 * ; 4 . \hat{Y}=87,470$ $-0,6520 F D N * *$; $. \hat{\mathrm{Y}}=-71,932+8,1268 F D N-0,1030 F D N^{2} * ; 6 . \hat{\mathrm{Y}}=-119,005+16,0263 F D N-0,2066 F D N^{2} * ; 7 . \hat{\mathrm{Y}}=1041,308-0,0776 F D N * *$ 8. $\hat{\mathrm{Y}}=-882,966+139,3555 F D N-1,8227 F^{2} N^{2} * ; \hat{\mathrm{Y}}=-758,121+118,5351$ FDN $-1,5492 \mathrm{FDN}^{2}$ *

*, ** $P<0,05$ e $P<0,01$, respectivamente, pelo teste $F(P<0.05$ and $P<0.01$ by $F$ test $)$. 
lado, o significativo decréscimo da produção de leite com o fornecimento da dieta de nível mais elevado de FDN proporcionou menor produção total de gordura (g/dia), sem alterar, contudo, sua concentração (\%).

Além da produção de leite e da alimentação, fatores inerentes ao animal, como raça, idade, peso, tamanho corporal e estádio de lactação, podem afetar a composição do leite (Bencini \& Pulina, 1997). Neste experimento, todas as ovelhas eram multíparas e com idades semelhantes, assim, as variações alheias aos tratamentos, que refletiram em baixos coeficientes de determinação $\left(\mathrm{R}^{2}\right)$, restringiramse a fatores individuais - tamanho corporal e herança genética.

O estádio de lactação influenciou significativamente a produção de leite dos animais $(\mathrm{P}<0,05)$, observando-se comportamentos quadrático, para aqueles alimentados com os níveis de 34 e 43\%, e linear, para o nível de 52\% de FDN na dieta (Tabela 5). A menor ingestão de nutrientes pode estar associada ao decréscimo linear verificado na produção de leite das ovelhas alimentadas com o nível mais elevado de fibra.
O pico da lactação para as ovelhas alimentadas com 34, 43 e 52\% de FDN ocorreu na terceira, segunda e primeira semanas de lactação, respectivamente. Bencini \& Pulina (1997) citam que o pico de produção ocorre entre a terceira e quinta semanas de lactação, discordando, parcialmente, de Church (1984), que relatou que o pico de lactação na espécie ovina ocorre entre a segunda e quarta semanas pós-parto. Por outro lado, Boujenane \& Lairini (1992) verificaram, em ovelhas das raças Sardi, D'man e seus cruzamentos, pico de produção na primeira semana de lactação, ao passo que Hassan (1995), em raças leiteiras, relatou que picos podem ocorrer mais tardiamente, em torno da sétima semana pós-parto. Após o pico, o declínio da produção de leite pode variar em função do tipo racial ou do potencial genético individual para a produção de leite (Bencini \& Pulina, 1997). Peeters et al. (1992) destacaram que o declínio na curva de lactação em ovelhas que permanecem com os cordeiros é explicado pela menor intensidade de sucção dos cordeiros, na medida em que estes se desenvolvem e começam a ingerir maior quantidade de alimento sólido.

Tabela 5 - Valores médios para a produção de leite ( $\mathrm{kg} / \mathrm{dia})$, de acordo com o período de lactação (dias)

Table 5 - $\quad$ Means values of milk yield (g/day) according to the lactation period (days)

\begin{tabular}{|c|c|c|c|c|c|c|c|c|c|}
\hline \multirow[t]{2}{*}{$\begin{array}{l}\text { Nível de FDN } \\
N D F \text { level }\end{array}$} & \multicolumn{6}{|c|}{$\begin{array}{l}\text { Dias } \\
\text { Days }\end{array}$} & \multirow[t]{2}{*}{$\mathrm{R}^{2}$} & \multirow[t]{2}{*}{$\mathrm{CV}$} & \multirow[t]{2}{*}{$\begin{array}{l}\text { Regressãc } \\
\text { Regressior }\end{array}$} \\
\hline & 7 & 14 & 21 & 28 & 35 & 42 & & & \\
\hline 43 & 1.828 & 1.901 & 1.880 & 1.799 & 1.415 & 1.198 & 0,43 & 18,64 & 2 \\
\hline 52 & 1.894 & 1.750 & 1.463 & 1.240 & 976 & 907 & 0,54 & 24,78 & 3 \\
\hline
\end{tabular}

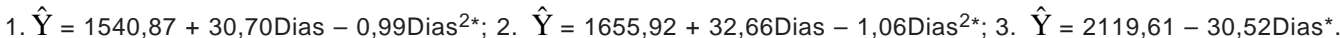

* $P<0,05$ pelo teste $F(P<0.05$ by $F$ test $)$.

Dias = dias em lactação (Days in milk).

\section{Conclusões}

Níveis superiores a 43\% de FDN na dieta limitaram o consumo de MS e a produção de leite das ovelhas.

A produção de leite relacionou-se diretamente ao consumo de MS.

O pico de lactação na espécie ovina pode ocorrer entre a primeira e terceira semanas pós-parto, dependendo do nível de fibra da dieta.

Os níveis de fibra das dietas estudadas afetaram a composição do leite ovino; contudo, estudos mais específicos acerca da efetividade desta fibra deverão ser realizados.

O nível de $40 \%$ de FDN pode ser recomendado para formulação de rações para ovelhas em lactação.

\section{Literatura Citada}

ASSOCIATION OF OFFICIAL ANALYTICAL CHEMISTS - AOAC Official methods of analysis. 16ed. Washington, D.C: 1995. $1141 \mathrm{p}$.

BENCINI, R.; PULINA, G. The quality of sheep milk: a review. International Journal of Sheep and Wool Science, v.45, n.3, p.182-220, 1997.

BOUJENANE, I.; LAIRINI, K. Genetic and environmental effects on milk production and fat percentage in D'man and Sardi ewes and their crosses. Small Ruminant Research, v.8, n.3, p.207215, 1992.

BRASIL - Ministério da Agricultura. Métodos analíticos oficiais para controle de produtos de origem animal e seus ingredientes: II. Métodos físicos e químicos. Brasília: Secretaria Nacional de Defesa Agropecuária, 1981. 87p.

BULL, L.S.; BAUMGARDT, B.R.; CLANCY, M. Influence of calorie density on energy intake by dairy cows. Journal of Dairy Science, v.59, n.6, p.1078-1086, 1976. 
BÜRGER, P.J.; PEREIRA, J.C.; SILVA, J.F.C. et al. Consumo e digestibilidade aparente total e parcial em bezerros holandeses alimentados com dietas contendo diferentes níveis de concentrado. Revista Brasileira de Zootecnia, v.29, n.1, p.206-214, 2000.

CARDOSO, A.R.; PIRES, C.C.; CARVALHO, S. et al. Consumo de nutrientes e desempenho de cordeiros alimentados com dietas que contêm diferentes níveis de fibra em detergente neutro. Ciência Rural, v.36, n.1, p.215-221, 2006.

CARVALHO, S.; RODRIGUES, M.T.; BRANCO, R.H. et al. Consumo de nutrientes, produção e composição do leite de cabras da raça Alpina alimentadas com dietas contendo diferentes teores de fibra. Revista Brasileira de Zootecnia, v.35, n.3, p.11531161, 2006. (supl.)

CHURCH, D.C. Alimentos y alimentacion del ganado. Montevideo: Hemisferio Sur, 1984. 404p.

DONEY, J.M.; PEART, J.M.; SMITH, W.F. et al. A consideration of the techniques for estimation of milk yield suckled sheep and a comparison of estimates obtained by two methods in relation to the effect of breed, level of production and stage of lactation. The Journal of Agricultural Science, v.92, n.1, p.123-132, 1979.

GAINES, W.L. The energy basis of measuring milk yield in dairy cows. Illinois Agricultural Experiment Station Bulletin 308, 1928. 40p.

HASSAN, H.A. Effects of crossing and environmental factors on production and some constituents of milk in Ossimi and Saidi sheep and their crosses with Chios. Small Ruminant Research, v.18, n.2, p.165-172, 1995.

JUNG, H.G.; ALLEN, M.S. Characteristics of plant cell walls affecting intake and digestibility of forages by ruminants. Journal of Animal Science, v.73, n.9, p.2774-2790, 1995.

LAMMERS, B.P.; BUCKMASTER, D.R.; HEINRICHS, A.J. A simple method for the analysis of particle sizes of forage and total mixed rations. Journal of Dairy Science, v.79, n.5, p.922928, 1996.

MERTENS, D.R. Creating a system for meeting the fiber requirements of dairy cows. Journal of Dairy Science, v.80, n.7, p.1463-1481, 1997.

MOREnO, J.A. Clima do Rio Grande do Sul. Porto Alegre: Secretaria da Agricultura, 1961. 41p.

NATIONAL RESEARCH COUNCIL - NRC. Nutrient requirements of sheep. 6ed. Washington, D.C.: National Academy Press, 1985. 112p.

NATIONAL RESEARCH COUNCIL - NRC. Nutrient requirements of dairy cattle. 6ed. Washington, D.C.: National Academy Press, 1989. 158p.

PEETERS, R.; BUYS, N.; ROBIJNS, L. et al. Milk yield and milk composition of Flemish milksheep, Suffolk and Texel ewes and their crossbreds. Small Ruminant Research, v.7, n.4, p.279288, 1992.

RUSSEL, A.J.F.; DONEY, J.M.; GUNN, R.G. Subjective assessment of body fat in live sheep. The Journal of Agricultural Science, v.72, p.451-454, 1969.

SAKUL, H.; BOYLAN, W.J. Evaluation of U.S. sheep breeds for milk production and milk composition. Small Ruminant Research, v.7, n.3, p.195-201, 1992.
STATISTICAL ANALYSIS SYSTEM - SAS. User's guide. Versão 6. 4.ed. Cary: 1997. 846p.

SILVA, P.H.F. Físico-química do leite e derivados. Juiz de Fora: Oficina de Impressão Gráfica, 1997. 190p.

SILVA, D.J.; QUEIROZ, A.C. Análise de alimentos: métodos químicos e biológicos. 3ed. Viçosa, MG: Editora UFV, 2002. 235p.

SIQUEIRA, E.R. Recria e terminação de cordeiros em confinamento. In: SILVA SOBRINHO, A.G.; BATISTA, A.M.V.; ORTOLANI, E.L. et al. (Eds.). Nutrição de ovinos. Jaboticabal: FUNEP, 1996. p.175-212.

SNIFFEN, C.J.; O'CONNOR, J.D.; Van SOEST, P.J. et al. A net carbohydrate and protein system for evaluating cattle diets: II. Carbohydrate and protein availability. Journal of Animal Science, v.70, n.11, p.3562-3577, 1992.

SUSIN, I.; LOERCH, S.C.; McCLURE, K.E. Effects of feeding a high-grain diet at a restricted intake on lactation performance and rebreeding of ewes. Journal of Animal Science, v.73, n.11, p.3199-3205, 1995.

SUSIN, I. Exigências nutricionais de ovinos e estratégias de alimentação. In: SILVA SOBRINHO, A.G.; BATISTA, A.M.V.; SIQUEIRA, E.R. et al. (Eds.). Nutrição de ovinos. Jaboticabal: FUNEP, 1996. p.109-141.

TREACHER, T.T. Nutrition of the dairy ewe. In: NORTH AMERICAN DAIRY SHEEP SYMPOSIUM, 1989, St-Paul. Proceedings... St-Paul: University of Minnesota, 1989. p.4555.

TURINO, V.F. Substituição da fibra em detergente neutro (FDN) do bagaço de cana-de-açúcar in natura pela FDN da casca de soja em dietas contendo alta proporção de concentrado para cordeiros confinados. Piracicaba: Universidade de São Paulo, 2003. 60p. Dissertação (Mestrado em Agronomia) - Universidade de São Paulo, 2003.

TYRRELL, H.F.; REID, J.T. Prediction of the energy value of cow's milk. Journal of Dairy Science, v.48, p.1215-1223, 1965.

Van SOEST, P.J. Nutritional ecology of the ruminant. 2.ed. Ithaca: Cornell, 1994. 476p.

WEISS, W.P.; CONRAD, H.R.; ST. PIERRE, N.R. A theoreticallybased model for predicting total digestible nutrient values of forages and concentrates. Animal Feed Science and Technology, v.39, n.1-2, p.95-110, 1992.

WOHLT, J.E.; KLEYN, D.H.; VANDERNOOT, G.W. et al. Effect of stage of lactation, age of ewe, sibling status, and sex of lamb on gross and minor constituents of Dorset ewe milk. Journal of Dairy Science, v.64, n.11, p.2175-2184, 1981.

ZEPPENFELD, C.C. Produção e composição do leite ovino e desempenho das cordeiras durante a lactação e ao desmame. Santa Maria: Universidade Federal de Santa Maria, 2003. 66p. Dissertação (Mestrado em Zootecnia) - Universidade Federal de Santa Maria, 2003.
Recebido: 18/9/2006 Aprovado: 15/5/2007 